Original Article

\title{
STRESS AM ONG EARLY ADOLESCENTS AND MATERNAL AND TEACHERS ROLE PERCEPTION IN ADDRESSING ADOLESCENTS' STRESS IN SELECTED SCHOOLS OF THIRUVANANTHAPURAM
}

\author{
Aswathy $K^{1}{ }^{1}$, Kasturi R A $\&$ Maxie $A^{3}$ \\ ${ }^{1}$ Assistant Professor, Government College of Nursing, Thiruvananthapuram, \\ ${ }^{2}$ Principal, Manipal School of Nursing, ${ }^{3}$ Assistant Professor, Department of Community Health Nursing, Manipal College \\ of Nursing, M anipal University, Manipal, Karnataka, India. \\ Correspondence : \\ Aswathy K L \\ Assistant Professor, Government College of Nursing, Thiruvananthapuram. \\ Mobile : +919846885280 E-mail : aswathyksaju@yahoo.co.in
}

\begin{abstract}
:
Objective: The objectives of the study were to assess the stress of early adolescents and to describe the role perceptions of mothers and teachers in addressing adolescent stress.

Materials and Methods: This quantitative descriptive survey was conducted in two phases in Thiruvananthapuram district, Kerala. Data were collected from early adolescent children (959), their teachers (61) and mothers (136). In the first phase, level of stress and source of stress among early adolescent children and teachers' role perception in addressing adolescent stress were measured. In the second phase, role perception in addressing their adolescent's stress was assessed among mothers of adolescents with high stress. Result: A total of 97 (10.1\%) adolescents had severe stress. M ajority of adolescents have cited mothers' and fathers' parenting role as their major stressor ( $56.5 \%$ and $53.5 \%$ respectively). M others reported that over watching of television is a major cause of lack of interest in studies and that is the main reason for stress at home. $37.7 \%$ of the teachers felt that school is giving a lot of academic stress to the child. Conclusion: The study finding calls for collective actions of student-teacher-parent associationsto reduce stress of adolescents.
\end{abstract}

Key words: Stress, Early adolescents, level of stress, source of stress, maternal role perception, Teachers' role perception.

\section{Introduction :}

Adolescence can be a challenging time for children, parents and teachers alike. Most often parents feel unprepared and they may view the years from 10 through 14 as a time just "to get through." ${ }^{1}$ Growing up-negotiating a path between independence and reliance on others-is a tough business. It creates stress, and it can affect the mental health status of young people ill-equipped to cope, communicate and solve problems. ${ }^{2}$ Adolescence, which literally means, 'to grow in to maturity', is generally regarded as the psychological, social

\begin{tabular}{|c|}
\hline Access this article online \\
\hline Quick Response Code \\
\hline
\end{tabular}

and maturational process by the pubertal changes. It involves three distinct sub phases: early adolescence, middle adolescence and late adolescence. ${ }^{3}$

Children are forced to listen messages regarding their safety and security. Moreover, fears and worries are prevalent during this period of development. ${ }^{4}$ Early adolescent children spend much of their waking hours in school-related activities. Thus teachers also contribute to the contextual environment of school-age children. ${ }^{5}$ Recent reports in the news-papers and media bring horrible pictures of the increasing adolescent suicide in India, especially in Kerala. In the year 2010, National Crime Bureau's study disclosed 1640 boys and 1490 girls committed suicide in India. ${ }^{6}$ Over expectation of the parents about their adolescent children in academic and extra -curricular activities and incapability of their adolescent boys and girls leads to adjustment problems in the students both at academic and societal level. This signifies the importance of assessing the level and source of stress among adolescents in Kerala. The objective of the study is to assess the stress of early adolescents and to describe the role perceptions of mothers and teachers in addressing this problem. This will 
help to design effective measures at family and community level to alleviate stress of adolescents.

\section{Materialsand methods:}

The study was a quantitative descriptive survey conducted in two phases in three randomly selected schools of Thiruvananthapuram district. In the first phase, level of stress and source of stress among early adolescent children and teachers' role perception in addressing adolescent stress were measured. In the second phase, role perception in addressing their adolescent's stress was assessed among mothers of adolescents with high stress. Population for the present study was early adolescent children in the age group of 10 to 14 years studying in 5th9th standard, their mothers and teachers. Estimated sample size was 900 . Total of 959 early adolescent children were included in the study. Samples of teachers in the present study were all teachers who were taking classes for the selected children and who were present during data collection. In the present study 61 teachers have participated in the study. In phase Il of the study mothers of early adolescent children were the samples for the study. All mothers of selected early adolescent children with high stress were selected as the sample. In the study 76 mothers were included in the study.

Multi stage Cluster sampling was used to select the early adolescent children. Self- report was used as the technique to collect data from early adolescent children, mothers and teachers. There were 6 tools used for data collection.

- Tool 1,2 and 3: Socio-demographic proforma of early adolescent children, mothers and teachers respectively.

- Tool 4: Adolescent stress assessment scale- has two sections.

Section 1: Assessment of level of stress: This section is a three point rating scale that are grouped under three domains of stress- intra-personal stress, inter-personal stress and extra-personal stress. Level of stress was measured as mild, moderate and severe based on mean and standard deviation.
Section 2: Assessment of source of stress: This is a three point rating scale that consists of 25 items in which the children has to rate either mild stressor, moderate stressor or severe stressor. The stressor items are grouped under three domains- intra-personal, inter-personal and extrapersonal stressors.

- Tool 5: Semi structured questionnaire to assess maternal role perception in addressing adolescents' stress: Consists of three domains- maternal role perception in prevention, detection and reduction of adolescent stress.

- Tool 6: Semi structured questionnaire to assess teacher's role perception in addressing adolescents' stress: Consists of three domains- teachers' role perception in prevention, detection and reduction of adolescent.

Reliability coefficient ' $r$ ' for adolescent level of stress scale was 0.8 and source of stress was 0.74 . Prior administrative permission was obtained. On the scheduled date questionnaire for collecting socio-personal details and stress assessment scale was given to the students. An average of 30 minutes was taken by each class to fill the tool. On the same day role perception of teachers in addressing adolescent stress was collected using semistructured questionnaire. In the second phase after analyzing the stress of early adolescent children, children with high stress were selected. Semi-structured questionnaire for assessing maternal role perception in addressing adolescent stress was send to mothers through children. Filled questionnaires were collected back.

\section{Statistical Methods :}

The obtained data were analyzed based on the objectives by using descriptive and inferential statistics. Frequency and Percentages were used to describe the demographic characteristics of sample, source of stress and role perceptions of mothers and teachers. Mean and SD was used to describe the level of stress. 
Results:

Section1. Socio-demographic data of early adolescents

Table 1: Frequency and percentage distribution of selected sociodemographic variables of early adolescent children $\quad(N=959)$

\begin{tabular}{|c|c|c|c|}
\hline SI No & $\begin{array}{l}\text { Socio-demographic } \\
\text { variables }\end{array}$ & Frequency & Percentage \\
\hline \multirow[t]{6}{*}{1} & Class & & \\
\hline & 5 & 191 & 19.9 \\
\hline & 6 & 200 & 20.9 \\
\hline & 7 & 180 & 18.8 \\
\hline & 8 & 196 & 20.4 \\
\hline & 9 & 192 & 20.0 \\
\hline \multirow[t]{3}{*}{2} & Gender & & \\
\hline & Boys & 428 & 44.6 \\
\hline & Girls & 531 & 55.4 \\
\hline \multirow[t]{4}{*}{3} & Number of children in th & mily & \\
\hline & Single child & 145 & 15.1 \\
\hline & Two children & 701 & 73.1 \\
\hline & More than two children & 113 & 11.8 \\
\hline \multirow[t]{5}{*}{4} & Birth order & & \\
\hline & First & 453 & 47.2 \\
\hline & Second & 455 & 47.4 \\
\hline & Third & 36 & 3.8 \\
\hline & More than three & 15 & 1.6 \\
\hline \multirow[t]{4}{*}{5} & Type of parenting & & \\
\hline & Both parents & 835 & 87.1 \\
\hline & Single parent & 52 & 5.4 \\
\hline & Father abroad & 72 & 7.5 \\
\hline
\end{tabular}

Section 2 : Level of stress of early adolescents

The mean of stress scores was 55.31 and the standard deviation was 12.75 .

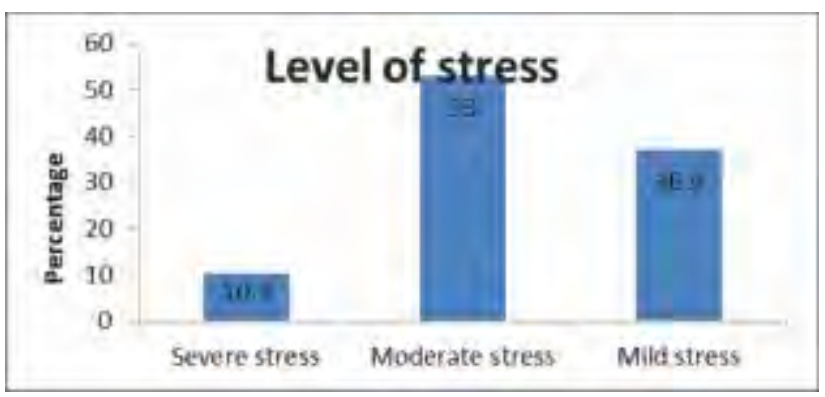

Fig 1: Distribution of early adolescent children according to their level of stress

\section{Section 3: Source of stress of early adolescents}

When assessing intrapersonal stressors, $28.6 \%$ samples reported physical health problems as highly stressful stressor whereas $20.2 \%$ of adolescents felt their loss of interest in studies as highly stressful factor. Among interpersonal stressors, majority of adolescents cited mothers' and fathers' parenting role as their major stressors (56.5\% and $53.5 \%$ respectively), 54\% perceived discrimination from parents as highly stressful. For $45.9 \%$ of children teachers were high stress inducing agents. $36.7 \%$ worried about their conflicts with siblings whereas only $13.7 \%$ of adolescents cited problems in friendship as their major stressor. In extra personal stressors, adolescents perceived poor housing $(44.6 \%)$, socioeconomic status (37.2\%), workload (40.6\%), and homework (36.2\%) as the major stressors.

Section 4. : Role perception of mothers of early adolescents in addressing adolescent stress.

Majority of mothers felt that children had stress due to academic reasons like difficulty in studies (61\%), inadequate time for leisure (44.8\%), lack of good friends (23.5\%), sickness and absenteeism (38.2\%) and economic problems (13.9\%). 8.3\% of mothers viewed domestic problems as a major stressor of children. More than half of the samples (51.4\%) complained that children spent too much time in watching television and play which causes lack of interest in studies and that is the main reason for stress at home. Only $41.9 \%$ of mothers agreed that they discuss matters freely with their children. Only $38.2 \%$ of mothers found time to visit school and meet teachers and discuss their children's school performance. $61.8 \%$ of mothers agreed that they knew the friends of their children very well. $16.9 \%$ of mothers in the selected sample had tried to find out the stress level of children and solve the problem. It was interesting to note that $94.1 \%$ of the selected mothers wanted to follow a friendly parenting style. 5.9\% showed interest in authoritarian parenting system. $53.7 \%$ of mothers tried to prepare a home environment which is contusive for her adolescent child to share and discuss his/her problems. $47.7 \%$ of mothers believed that discipline and punishment is necessary for the character development of the adolescent child. M others viewed school as the best place for molding the child's individuality and character. Child should learn strategies for coping with stress from the school itself.

Mothers explored the strategies to adopt in order to 
prevent, reduce and manage stress among early adolescent children.

Section 5: Role perception of teachers of early adolescent children in addressing adolescent stress.

$96.7 \%$ of the teachers agreed that their adolescent students had stress and there are genuine reasons for their stress: school is giving a lot of academic stress to the child (37.7\%); teachers find time to talk with their students other than the academic matters (96.7\%); able to recognize the features of stress in their students (85.2\%); allowed the students to discuss their personal problems with them (91.8\%). Teachers expressed strategies for preventing, reducing and managing stress in early adolescent children.

\section{Discussion:}

The present study found that $10.1 \%$ of adolescents had severe stress, $53 \%$ had moderate stress and $36.9 \%$ had mild stress. Mean stress score was 55 and standard deviation was 12. Majority of adolescents experienced moderate stress.

A study in Kerala among children in the age group from 4 to 17 years where severe stress was $1.9 \%{ }^{8} \mathrm{~A}$ study held in Brazil by C. R. Sbaraini and L. B. Schermann revealed a higher level of stress (27.2\%) among adolescents over 10 years. $^{9}$

It was baffling to note that early adolescents (56.5\% and $53.5 \%)$ felt that parents and teachers were the stress inducers. Being impulsive and closer to peers rather than parents and teachers is a part of adolescence. Being

\section{References:}

1. Helping your child through early adolescence. U.S. Department of Education Office of Communications and Outreach. Washington DC. 2005.

2. Walker J. Teen in distress series Adolescent Stress and Depression.[Internet]. 2005. Available from http://www.extension. umn.edu/ distribution/ youth development/ da3083.html

3. Wong DL. Whaley and Wong's Nursing care of infants and children. $6^{\text {th }}$ ed. M osby. 1996. P 448-450.

4. Brown SL, Teufel JA, Birch DA, Kancherla V. Gender, age, and behavior differences in early adolescent worry. J Sch Health. 2006 Oct; 76(8):430-7.

5. Carolina M. Teaching with affection: characteristics and Determinant factors of quality in teacher student relationships [Internet]. Available controlled by teachers and parents like coming home in time, not spending too much time on outdoors, television and games, being punctual and complying with homework etc may be construed as stressors by adolescents. Eventhough mothers agree that their child is stressed, they do not perceive that their parenting style had an influence on their stress. The finding of the present study signifies the importance of exploring the parenting styles and attitude of mothers in caring their adolescent children.

\section{Conclusion :}

Study revealed that in the current scenario of societal and educational setup, early adolescents are experiencing stress. M ajor stressors of early adolescent children were identified from the home and school environment. Stressors that were identified as highly stressful were parenting role of parents, teachers, work load, home-work, high expectation of parents, parental conflicts, economic factors etc. Study also identified that mothers and teachers perception in addressing adolescent stress was not related either to their parenting or teaching behaviours. Inspite of mothers and teachers recommendations of suitable strategies to prevent stress among adolescents at school or home, early adolescent children had identified them as their stressful factors. This indicates that there guidance is required for mothers or teachers in identification of stress of adolescents. School administration should plan strategies to prevent and reduce stress of academics. I n the present study there is uncertainty of data as the investigator could not directly meet the mothers for data collection.

at revistaiaf.abacolombia.org.co/en/pdf/v1n1/v1n1 2 en.pdf

6. National Crime record bureau. India. 2010[Internet].A-Available from http://ncrb.nic.in/

7. Varni JW. PedsQL ${ }^{\mathrm{TM}}$ (Pediatric Quality of Life Inventory).M API research trust available at www.pedsql.org

8. Sapna D. Prevalence of stress among school children in Kerala. Available at http://www.articlesbase.com/mental-healtharticles/prevalence-of-stress-among-school-children-in-kerala1868702.htmlPosted: Feb 17, 2010.

9. Sbaraini CR, Schermann LB. Prevalence of childhood stress and associated factors: a study of schoolchildren in a city in Rio Grande doSul State, Brazil.CadSaudePublica. 2008 M ay;24(5):1082-8. 